\title{
Assessing, monitoring and managing continuous intravenous sedation for critically ill adult patients and implications for emergency nursing practice: A systematic literature review
}

\author{
Wayne Varndell, MN (Research), BSc (Hons) Nursing, GradDip (AP), \\ PGCert (Ed.) a,b,* \\ Doug Elliott, BAppSc (Nursing), MAppSci (Nursing), PhD ${ }^{\mathrm{b}}$ \\ Margaret Fry, NP, BAppSc (Nursing), MEd, PhD ${ }^{c, b}$
}

\footnotetext{
a Prince of Wales Hospital, Emergency Department, Barker Street, Randwick, NSW 2013, Australia

b Faculty of Health, University of Technology, Sydney, 15 Broadway, Ultimo, NSW 2007, Australia

' School of Nursing, University of Sydney, Australia
}

Received 13 June 2014; received in revised form 5 August 2014; accepted 10 August 2014

\section{KEYWORDS \\ Sedation; \\ Nursing practice; \\ Critical care}

\begin{abstract}
Summary
Background: Critically ill mechanically ventilated patients in ED have complex needs; chief among these is adequate sedation in addition to effective pain-relief. Emergency nurses are increasingly responsible sedation and analgesia for this complex cohort of patients. The aim of this review was to examine (1) the evidence around assessing, monitoring and managing continuous intravenous sedation for critically ill adult patients, and (2) the implications for emergency nursing practice.

Study design: Systematic review.

Method: The review of literature extended from 1946 to 2013 and examined peer review journal articles, policy and guidelines to provide a more complex understanding of a phenomenon of concern. A total of 98 articles were incorporated and comprehensively examined.
\end{abstract}

\footnotetext{
* Corresponding author at: Prince of Wales Hospital, Emergency Department, Barker Street, Randwick, NSW 2031, Australia. Tel.: +6129382 3910 .

E-mail addresses: wayne.varndell@sesiahs.health.nsw.gov.au, waynevarndell@mac.com (W. Varndell), doug.elliott@uts.edu.au (D. Elliott), margaret.fry@uts.edu.au (M. Fry).
} 
Results: Analysis of the literature identified several implications for emergency nursing practice and the management of continuous intravenous sedation: workload, education, monitoring and assessing sedation and policy.

Conclusion: Limited literature was found that directly addressed Australasian emergency nursing practices' in managing on-going intravenous sedation and analgesia for patients. Balancing patient sedation and analgesia requires highly complex knowledge, skills and expertise; the degree of education and training required is above that obtained during pre-registration nurse training. No state or national models of education or training were identified to support ED nurses' practices in managing sedation. Little research has addressed the safety of continuous sedation use in ED.

(c) 2014 College of Emergency Nursing Australasia Ltd. Published by Elsevier Ltd. All rights reserved.

\section{What is known}

- The number of critically ill patients admitted to EDs has increased by over $25 \%$, some of whom require mechanical ventilation and continuous intravenous sedation.

- Emergency nurses working in the resuscitation area are increasingly responsible for the management of analgesia and sedation for critically ill patients, which requires highly developed skills, knowledge and expertise.

- Adequate analgesia and sedation are paramount in optimising comfort, pain-relief and well-being of critically ill patients, who are often inflicted with a wide range of noxious stimuli with limited physiological reserves.

\section{What this paper adds}

- There is little research exploring the role of the emergency nurse in managing continuous intravenous analgesia and sedation for critically ill mechanically ventilated patients.

- Research and policy have primarily focused upon the safety and effectiveness of procedural sedation administered in ED.

- Unlike other roles emergency nurses undertake (e.g. Triage), there are no practice standards, education or training programs to support nurses transitioning into the resuscitation nurse role, and to manage of continuous intravenous analgesia and sedation for critically ill mechanically ventilated patients.

\section{Introduction}

Two areas of practice involving the use of sedation have emerged within the emergency department setting. The first area concerns procedural sedation to enable patients to tolerate succinct, definitive interventions such as cardioversion, orthopaedic procedures, incision and drainage and insertion of chest drains. The second area involves the critically ill patient group, who often require continuous sedation to tolerate necessary life-supporting invasive, agitating and painful interventions such as mechanical ventilation and endotracheal intubation. ${ }^{1}$ While the incorporation and effectiveness of procedural sedation in ED has been well documented, ${ }^{2-6}$ the safety and effectiveness of continuous intravenous sedation in ED has not. ${ }^{7}$ Emergency nurse are responsible for the continuity of patient care, assessment, monitoring and optimisation of sedation and pain control for critically ill sedated patients. Emergency nursing practice often occurs in isolation due to geographical layout of the resuscitation area and workload demands of other clinicians. Therefore, the safety and effectiveness of continuous intravenous sedation for the critically ill adult patient in ED is dependent on the skill, knowledge and decision-making abilities of the emergency nurse.

Adequate sedation and analgesia are paramount in optimising comfort, pain relief and wellbeing of critically ill mechanically ventilated patients, ${ }^{8}$ who are inflicted with a barrage of noxious stimuli and invasive procedures such as insertion of endotracheal tubes, central venous catheters, indwelling urinary catheters and monitoring devices. Critically ill or injured patients require sedation and analgesia balanced to their needs and physiological tolerances. ${ }^{2,6}$ Within the ED, emergency nurses are increasingly responsible for managing sedation and analgesia of critically ill patients, ${ }^{9}$ therefore the knowledge, skills and expertise of the emergency nurse are paramount for maintaining patient comfort, wellbeing and safety. The aim of this systematic literature review was to examine (1) the evidence around assessing, monitoring and managing continuous intravenous sedation for critically ill adult patients, and (2) the implications for emergency nursing practice. We also define areas of education, research, policy and standards that have not been covered and suggest some potential courses of action.

\section{Review search strategy}

The search covered the period from 1946 to 2013. No date or language restrictions were applied. Several search terms were used to identify potential studies concerning the assessment, monitoring and administering continuous intravenous sedation for the critical ill adult (>16 years) patient in ED: 'assessment AND sedation AND emergency department', 'sedation AND emergency department', 'continuous sedation', 'emergency OR nurse AND sedation', 'measuring sedation' and 'sedation scale'. A total of 210 articles 


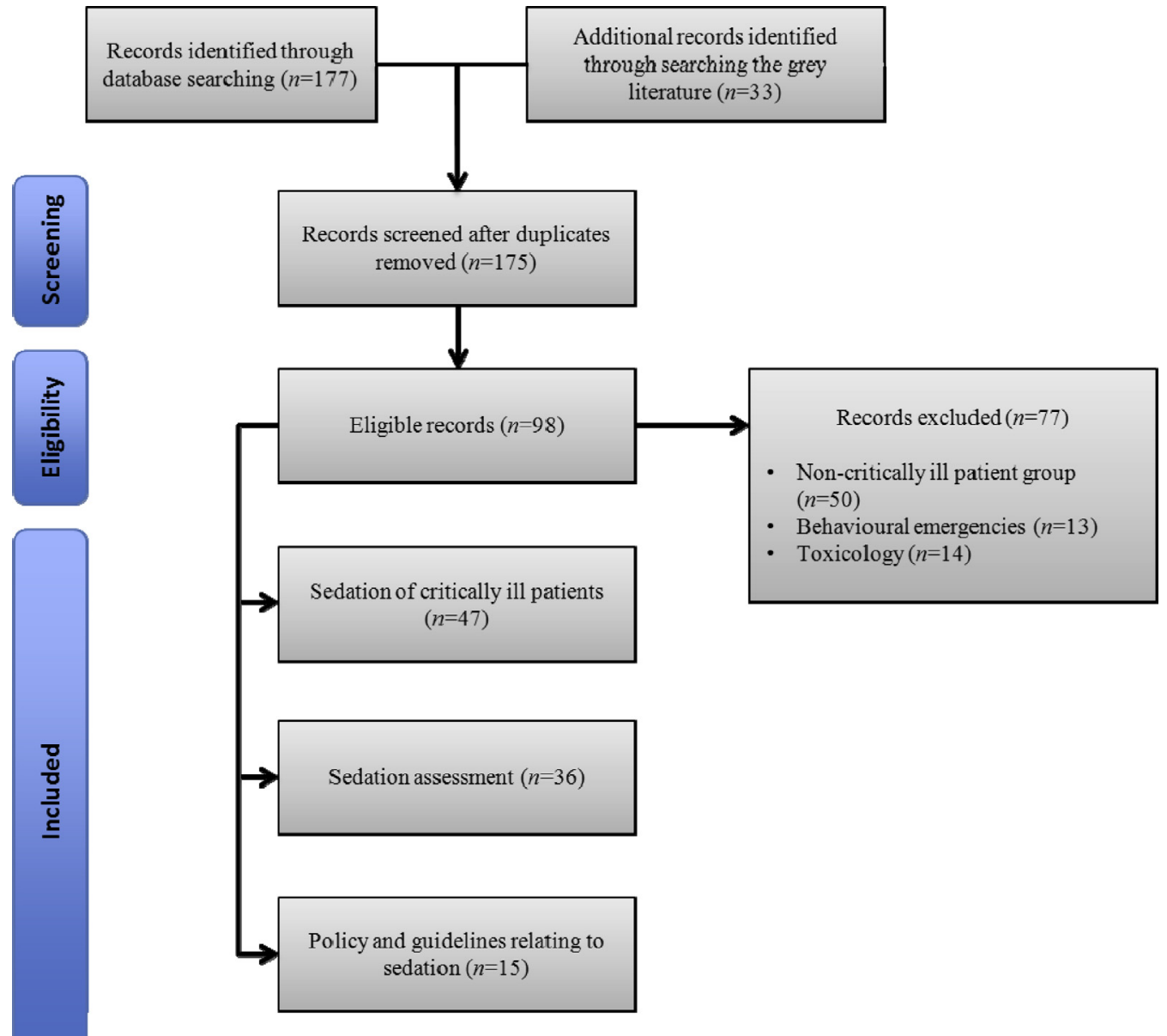

Figure 1 Search results.

were initially identified using the above search terms. After removing duplicate records $(n=35) 175$ articles remained. Of the 175 articles, 77 (44\%) were excluded as they lacked relevance to any aspect of the research question. Of the total articles $(n=210)$ identified, $98(47 \%)$ were incorporated and comprehensively examined using the Critical Appraisal Skills Program 'Making Sense of Evidence Tools' ${ }^{10}$ (Fig. 1).

\section{Databases accessed}

A systematic literature search was conducted using the following databases: Cumulative Index to Nursing and Allied Health Literature, EMBASE, Medline, ProQuest and Science Direct. The Cochrane Library and the National Institute of Clinical Excellence databases were also searched. The review was supplemented with a manual search of reference lists from relevant research studies and grey literature. Grey literature included organisational and professional associations related to emergency, sedation or critical care and Google Scholar. The grey literature was explored for policies, guidelines and recommendations relating to sedation.

\section{Results}

The literature review revealed a number of areas of importance relating to the management of critically ill patients receiving continuous intravenous sedation, which have implications for emergency nursing practice. Analysis of the literature highlighted the highly complex knowledge, skills and expertise required by nurses to safely manage sedation for the critically ill patient, which is above that obtained in pre-registration nurse training. This in turn highlighted the issue of post-registration education and training of emergency nurses in the sub-speciality role of resuscitation nurse; an essential precursor to safely managing sedation for critically ill patients in the resuscitation area. Further analysis of the literature revealed an increased focus on the assessment of sedation with validated observation sedation scoring tools, and that in the absence of their use, it was noted to negatively impact upon the quality of clinician communication and responsiveness to patients' sedation needs.

\section{The emergency nurse and the resuscitation area}

Emergency nurses undertake numerous clinical activities, often simultaneously or for multiple critically ill patients while working within the resuscitation area. A recent study by Green et al. ${ }^{11}$ examined the impact of critical care procedures conducted in the ED. The ED retrospective medical record audit of critical care patients $(n=178)$ identified that the majority $(80 / 125,64 \%)$ of procedures related to 
endotracheal intubation, insertion of central venous $(3 / 10$, $30 \%)$ and arterial $(14 / 99,14 \%)$ catheters, and chest tube insertion $(4 / 8,50 \%)$. Green et al. concluded that while critically ill patients were managed in the ED for a considerable length of time (mean $6.5 \mathrm{~h}$, median $4.9 \mathrm{~h}$, range 1.4-28.2 h), critical care ED procedures conducted did not impact on overall patient length of stay. This finding was consistent with other authors. ${ }^{12-15}$

A study by 0 'Connor et al. ${ }^{16}$ and colleagues calculated nursing care time using the Therapeutic Intervention Scoring System-28 (TISS-28) based on documented resuscitation area clinical interventions. In the retrospective medical record audit of critically ill ED patients $(n=69)$ the median TISS-28 score for patients was 19 (range 9-34). One TISS-28 point equates to $10.6 \mathrm{~min}$ of each $8 \mathrm{~h}$ nurses' shift. Therefore, the range of nursing care time per patient was $95-360 \mathrm{~min}$ $(1.6-6 \mathrm{~h})$, with a median value of $201 \mathrm{~min}(3.4 \mathrm{~h})$. The total demand on nursing care time for patients was 13,356 min ( $222 \mathrm{~h}$, or 9.25 days). Comparatively, in a time-and-motion study examining the impact of critically ill patients $(n=50)$ and emergency physician workload, Graff et al. ${ }^{17}$ calculated that the median time demand was $32 \mathrm{~min}(0.5 \mathrm{~h})$ of doctors' time per patient.

Importantly, ED physicians rely on emergency nurses allocated to the resuscitation bay to assess, monitor and initiate care to maintain patient safety and welfare, and consultative input from intensive care medical specialists. ${ }^{18}$ In the ED, emergency physicians are unable to provide continuous care to critically ill patients given that they manage the needs of other patients. Therefore, management of critically ill patients and the role of the emergency nurse in providing care is essential to optimising patient outcome and survival. ${ }^{19,20}$ Nonetheless, there is a paucity of literature of how emergency nurses undertake care practices within the resuscitation area for critically ill patients.

Emergency nurses manage critically ill patients for increasing lengths of time in the resuscitation bay until they transfer the patient to the intensive care unit (ICU). ${ }^{7,19}$ In Australia, Carter et al. ${ }^{21}$ retrospectively explored the relationship between ED length of stay (LOS) for critically ill patients $(n=48,803)$ and ICU mortality across 45 hospitals. It was noted that the majority $(n=39470,81 \%)$ of severely ill patients had a median LOS of $3.9 \mathrm{~h}$ (IQR 2.0-6.8) in ED, with nearly one fifth $(n=9273 ; 19 \%)$ of patients spending longer than $8 \mathrm{~h}$ in the ED prior to transfer to the ICU. In a later prospective study conducted in Brazil, Cardosa et al. ${ }^{22}$ found a significant $(p=0.002)$ increase in mortality for patients delayed in being admitted to ICU. The mortality risk attributable to ICU delay was 30\% (95\% Cl: $11.2-44.8 \%)$, with each hour of delay independently associated to an increased risk of ICU death of 1.5\% (hazards ratio: 1.015; 95\% Cl 1.006-1.023; $p=0.001)$. These studies demonstrate that critically ill patients are staying longer in ED and so increasing the importance of the role of the emergency nurse given that they provide much of the on-going care while the patient waits to be transferred to ICU.

Many patients while awaiting transfer to an ICU require on-going assessment by emergency nurses to determine care needs. More specifically, emergency nurses will reassess the patient to determine the on-going need for intravenous sedatives, analgesics and or paralysing agents. The literature suggests that the nurse's use of sedatives, analgesics and paralysing agents is to ensure the comfort and stability of the patient and interventions such as mechanical ventilation. Hence, emergency nurses are relied on to frequently assess for and manage continuous intravenous sedation infusions. The emergency nurse is essential to ensuring the safe management of the critically ill patient receiving continuous intravenous sedation infusions in the ED until the patient is transferred to ICU. ${ }^{23}$

\section{Knowledge and skills in managing sedation}

The degree of knowledge and skills required to safely manage sedation for a critically ill patient is highly complex, and is an integral part of critical care. ${ }^{24}$ Sedative agents are administered in an attempt to reduce anxiety and promote comfort. However, managing the sedated critically ill mechanical ventilated patient also requires knowledge and skills in the use of non-invasive and invasive equipment (e.g. mechanical ventilators, arterial lines and syringe drivers), being able to interpret and integrate diagnostic and physiological examination results into clinical decision-making, have a detailed understanding of the role and use of a broad range of pharmacological agents such as sedatives, analgesia, paralysing agents and anticipating and prioritising life-threatening medical problems with limited information and resource management. 7,8,24 Developing knowledge, skills and expertise therefore demands specialised training and education above that which is provided at a pre-registration level. While a review of the literature identified standardised state-based education programs to support nurses transitioning into emergency nursing practice, ${ }^{25}$ Triage, ${ }^{26}$ and the Clinical Initiatives Nurse role, ${ }^{25}$ no Australian or state-based education programs or professional standards have been published relating to preparing emergency nurses for the role of resuscitation nurse and the critically ill sedated patient. Historically, EDs have developed educational programs to assist nurses to undertake various clinical roles in the absence of formal training programs. ${ }^{27-29}$ Transitioning, the process of assuming and developing into a new role, is commonly experienced by emergency nurses throughout their careers as they achieve certain levels of experience, expertise and competence. ${ }^{30}$

Transitioning into a new work role has long been identified as a difficult process, ${ }^{31}$ and more recent research demonstrates the process remains daunting. ${ }^{32}$ Self-directed learning and supervised practice are common approaches used in clinical education to help transitioning practitioners assimilate and apply clinical concepts to new patient care situations. ${ }^{33,34}$ However, such informal approaches are constrained and variable. ${ }^{35,36}$ In addition to developing sufficient levels of knowledge, skills and expertise, developing confidence is a process that requires time and the ability to apply the knowledge, skills and decision-making in an applicable setting. ${ }^{37}$ As Weinert et al. ${ }^{38}$ and Guttormson et al. ${ }^{39}$ demonstrated, obtaining critical care experience prior to transitioning into the role of the resuscitation nurse was associated with increased confidence in managing critically ill patients, and in managing and adjusting sedation and analgesia. 


\section{Monitoring sedation in critically ill patients}

Critically ill patients' haemodynamic status can change minute-by-minute, and therefore monitoring is a crucial part of the care of the critically ill patient in the ED, as the physiological response to critical illness is linked strongly to outcome. The term 'vital signs' is generally used to describe a set of physiological measures that includes heart rate, blood pressure, respiratory rate, temperature, peripheral oxygen saturation, pain severity/level and level of consciousness. Patient vital signs are commonly used by nurses as a means of providing objective information about a patient's response to sedation. ${ }^{40}$ Vital signs are measured and recorded electronically through monitors attached to the patient, and displayed in continuous real-time on monitors located at each patient's bed space. While emergency nurses rely on evaluating vital sign information to regulate and manage critically ill patients requiring sedation, research suggests that other physiological indicators of sedation are also important. Young ${ }^{41}$ argued that the depth of sedation must be individualised to the patient's injuries or condition and sedation needs. If the indication for sedation is one of injury prevention, a lighter state of sedation may be aimed for to allow the patient to communicate with staff. ${ }^{42}$ If the indication for sedation is to facilitate an individual clinical goal, the sedation level may need to be somewhat deeper. ${ }^{41}$ For the emergency team achieving and maintaining a specific depth of sedation without jeopardising patient or staff safety, requires significant on-going nursing vigilance. ${ }^{43}$

Patients' responses to sedation can be unpredictable; not only within and between patient populations, but also within a single hospital stay for an individual patient. ${ }^{1,44-46}$ Hence, the challenge for emergency nurses in maintaining an appropriate depth of sedation suitable to the critically ill patient's needs and metabolic capabilities also requires on-going monitoring of the patient's neurological status. ${ }^{47}$ Emergency nurses therefore require expert skill and knowledge to respond to events such as drug accumulations, minute-by-minute changes in the patient's physiological status, changes in renal, liver and endocrine function and the synergistic or drug-to-drug interactions to increase or decrease the effectiveness of sedation.

\section{Sedation assessment}

Intravenous sedation has been associated with higher levels of patient mortality, ranging from $30 \%$ to $52 \% .{ }^{48,49}$ Excessive administration of intravenous sedation can depress protective airway reflexes such as coughing and gagging, and thereby increase the risk of passive regurgitation and aspiration of gastric contents. Complications and adverse events have been noted to arise from maintaining patients at deeper sedation levels than necessary. ${ }^{47}$ It is therefore critical that emergency nurses, in addition to frequently assessing the physiological state of the patient, also ascertain whether it is sedation that is required or pain relief. Aiken $^{50}$ suggested that the physiological data typically gathered by emergency nurses, may assist in determining the type and quantity of pharmacological agents to support care practices. Typically, sedation assessment involves gathering information, both physically and physiologically. ${ }^{7}$ Physical information can alert the emergency nurse that the patient requires an alteration in sedation treatment. Examples include: head thrashing and pulling at invasive lines/devices such as intravenous cannula or indwelling urinary catheter. Physiological data provides the means for understanding different components of consciousness that create a more comprehensive overall picture of the patient's sedation level and requirements. Physiological information includes: increased breathing rate, cardiac changes, radiographic data and laboratory findings. Sedation management is highly complex. Undertaking sedation management demonstrates advanced skill and knowledge for understanding how physiological changes may reflect sedation and analgesic patient need. ${ }^{50}$ Further, there is growing evidence to suggest that observational sedationscoring assessment tools may enhance nursing management of sedation of critically ill patients receiving continuous sedation.

Within the literature, the only common tool used within the ED setting to assess patient depth of sedation was the Glasgow Coma Scale. ${ }^{51}$ The GCS however, was not developed to measure sedation but was designed to objectively measure and quantify the prognosis of a brain injured patient. ${ }^{52-56}$ Furthermore, it is not supported within the context of assessing, monitoring and administering sedation. ${ }^{57-60}$ The literature review identified 27 observational sedation assessment tools developed and tested with varying degrees of validity, reliability, responsiveness and applicability in the critically ill patient population. Observational sedation assessment tools have been developed by various authors, and are similar in form and format. The tools rate the level of sedation based upon a single direct observation and interaction with the patient such as in response to applying a noxious stimulus. In the literature review there was no evidence that sedation tools have been developed or tested within the ED setting. However observational sedation-scoring tools have been developed and validated within the intensive care setting, supporting ICU nurses to determine when and how to adjust sedative dosages. Use of sedation-scoring assessment tools in critical care environments has been demonstrated to improve nurse assessment and titration of sedation. ${ }^{39}$ Further, nurses' attitudes towards the efficacy of sedation for mechanically ventilated patients, their sedation practices and confidence to administer sedation improved when using observation sedation-scoring tools. ${ }^{57,61}$ A key factor that differentiated between those utilising sedation-scoring tools concerned the improved quality of communication between the nurse and physician. ${ }^{62}$ In a recent multicentre $(n=41)$, bi-national (Australian and New Zealand) point prevalence study ${ }^{63}$ of ICU patients $(n=569)$ and the assessment and management of analgesia, sedation and delirium, four observational sedation-scoring scale tools were commonly used: Ramsey Sedation Score, ${ }^{64}$ Sedation-Agitation Scale, ${ }^{65}$ Motor Activity Assessment Scale ${ }^{66}$ and the Richmond Agitation and Sedation Scale. ${ }^{67}$ These scales could be explored within the ED setting. Further, by using the same sedation-scoring scale as ICU, continuity of care may be increased. 


\section{Sedatives and the critically ill patient}

Agitation and anxiety occur frequently in critically ill patients and are associated with adverse clinical outcomes, to which sedatives are commonly administered. ${ }^{68}$ Sedation, as $\mathrm{Jacobi}^{69}$ described it, is part of a continuum of decreasing levels of consciousness, caused by the effect of sedatives on the brain. Historically, within the ICU setting, benzodiazepines and propofol have been commonly used to sedate critically ill patients. Recent surveys examining sedation practices in ICU demonstrate that midazolam and propofol remain common sedatives of choice in maintaining patient sedation. ${ }^{70-74}$ Sedatives can be titrated to maintain the patient at a light level (i.e. patient is arousable and able to follow commands) or deep sedation (i.e. patient is unresponsive to painful stimuli). Multiple studies $^{47,75-88}$ have examined depth of sedation in relation to several clinical outcomes: duration of mechanical ventilation, ICU length of stay, physiologic/psychological stress. Results of these studies suggest that maintaining critically ill patients at a light level of sedation is favourable compared to deep sedation, ${ }^{47,75-79}$ yet not all studies agreed. ${ }^{81,84,85}$ Three studies demonstrated increased physiologic stress in terms of raised catecholamine levels, and increasing oxygen consumption. ${ }^{81,84,85}$ The clinical significance of this is unclear, as no clear relationship between catecholamine levels and clinical outcomes, such as myocardial ischemia, was reported. ${ }^{81-83}$ The overall quality of evidence examining depth of sedation and physiologic stress is low, and has produced conflicting results. Despite conflicting results, it is currently recommended that critically ill patients should be maintained at a light level of sedation, as the benefits of being lightly sedated appear to outweigh the risks if appropriately titrated. ${ }^{49}$

Inadequate titration of sedatives can lead to increased patient agitation and injury, and decreased patient safety. Patient agitation may result in unplanned selfextubation, increased oxygen consumption, haemodynamic instability, injury to self or others, and an inability to participate in therapeutic interventions (e.g. mechanical ventilation). Agitation is described as excessive restlessness, characterised by non-purposeful mental and physical activity due to internal tension and anxiety. ${ }^{69,89}$ Agitation occurs often in the critically ill or injured patient as a result of inappropriate levels of sedation..$^{90,91}$ However, prompt identification and treatment of other possible causes of agitation, such as pain, delirium, hypoxiaemia, hypoglycaemia, hypotension, or withdrawal from alcohol and other drugs is also important. ${ }^{49}$

To date, the risk of complications and adverse events in relation to critically ill or injured patients receiving on-going intravenous sedation in the $E D$ is largely unknown in Australia. ${ }^{7}$ Critically ill patients, with reduced capacity to independently maintain optimal homeostasis, are vulnerable to deterioration in the presence of improperly managed sedation. The assessment, monitoring and resuscitation skills of the emergency nurses are therefore critical to maintaining appropriate sedation levels for critically ill patients. ${ }^{92}$

\section{Sedation policies and guidelines for nurses}

The American Nurses Association ${ }^{93}$ recommended that registered nurses who administer and monitor procedural sedation and analgesia be able to identify and differentiate the various levels of sedation; demonstrate the acquired knowledge of anatomy, physiology, pharmacology, cardiac dysrhythmia recognition; detect complications related to moderate analgesia and sedation and appropriately intervene; demonstrate competence in pre-procedural, procedural, and post-procedural nursing care from the initial patient evaluation to patient discharge; anticipate, recognize, and address potential complications during the process; and, understand the medico-legal aspects of procedural analgesia and sedation.

There is however no evidence of any Australian emergency nursing policies and/or standards of practice unlike, the USA ${ }^{9,94}$ and Canada. ${ }^{5,95}$ Conversely, medical guidelines have been published in Australia, ${ }^{44}$ the UK, ${ }^{96,97}$ Canada $^{5}$ and the USA ${ }^{9,93,94,98-100}$ to ensure that sedation is performed with optimal safety for the patient and to diminish risks for medical clinicians.

\section{Discussion}

Our review of the literature reveals that the knowledge, skills and expertise required by emergency nurses ${ }^{9}$ to safely balance time-sensitive procedures, medical therapies with pharmacological agents in the presence of patient haemodynamic instability and limited physiological reserves, is highly complex. ${ }^{50}$ Continuity of care for the critically ill patient remains the responsibility of emergency nurses, and is therefore dependent upon the knowledge, skill and expertise of emergency nurses until the patient is transferred to an ICU. The specialised skills, abilities and knowledge necessary to safely care for critically ill or injured patients receiving continuous sedation in the resuscitation bay remain unclear. While obtaining critical care experience prior to transitioning into the role of the resuscitation nurse was associated with increased confidence in managing critically ill patients, and in managing and adjusting sedation and analgesia, this has not been explored within the ED setting. To date, little research has been published focusing upon the practices' of emergency nurses managing continuous intravenous sedation for critically ill patients in the ED. Emergency nurses need to be able to assess for and manage the required and appropriate depth of sedation and provision of analgesia for critically ill patients. ${ }^{41,47,74}$ The review identified several validated observational sedation-scoring tools however these have not been trialled in ED. Future research should include exploring the use of an observational sedation-scoring tool within the ED setting.

Current research concerning sedation in ED has largely focused upon procedural sedation conducted with haemodynamically stable patients, physician approach and pharmaceutical choice. Research is needed to examine the use of continuous intravenous sedation in ED, and emergency nursing practices in managing sedation for this complex patient cohort. Nursing clinical practices in managing continuous sedation is highly complex, as such, policy and 
education need to be developed to provide guidance and credentialing for what is seen as advance practice.

\section{Limitations}

Identification of studies was done by one reviewer and selection bias may need to be considered. Identification and review of the literature, may have resulted in selection bias and this needs to be considered. There may have been a language bias as non-English articles were excluded. However, strengthening this review was the extensive database search and chronological review of literature. While some grey literature was captured by the search strategy, not all may have been identified.

\section{Conclusion}

To date, limited literature was found that related specifically to Australasian emergency nursing safety, assessment, monitoring and methods of management for the on-going intravenous sedation of patients. However, balancing the critically ill patient's sedation level appears to be a highly complex activity that is regularly undertaken by ED nurses in a time-sensitive and highly pressured environment. While international tools, policies and guidelines exist to optimise sedation practices, these appear not to be used within Australian emergency settings. While numbers of ED patients receiving continuous sedation has increased, it remains unclear how Australian emergency nurses manage continuous intravenous sedation in the critically ill patient. To date no Australasian policy or guidelines articulate the role of the emergency nurse in managing sedation in the critically ill patient. Yet, it is the emergency nurse that is responsible for the on-going assessment sedation practices for the critically ill patient.

\section{Provenance and conflict of interest}

All work contained within this manuscript is original and our own, unless otherwise acknowledged and is not under publication or review elsewhere. The authors have no financial or other conflict of interest other than one of the authors, Professor Margaret Fry, who is on the journal's international editorial advisory board. This paper was not commissioned.

\section{Funding}

This paper did not receive any funding from any source in relation to this research.

\section{References}

1. Rowe K, Fletcher S. Sedation in the intensive care unit. Cont Educ Anaesth Crit Care Pain 2008;8(2):50-5.

2. Bahn E, Holt K. Procedural sedation and analgesia: a review and new concepts. Emerg Med Clin N Am 2005;23:503-17.

3. Burton J, Asher S. Update on Emergency Department procedural sedation and analgesia. Emerg Med Crit Care Rev 2006:14-6.
4. Hohl C, Sadatsafavi M, Nosyk B, Anis A. Safety and clinical effectiveness of midazolam versus propofol for procedural sedation in the emergency department: a systematic review. Acad Emerg Med 2008;15:1-8.

5. Innes G, Murphy M, Nijessen-Jordan C, Ducharme J, Drummond A. Procedural sedation and analgesia in the emergency department. Canadian Concensus Guidelines. J Emerg Med 1999;17(1):145-56.

6. Miner JR, Martel M, Meyer M, Readon R, Biros MH. Procedural sedation of critically ill patients in the emergency department. Emerg Med 2005;12:124-8.

7. Rose L, Gerdtz M. Invasive ventilation in the emergency department. Part 2. Implications for patient safety. Australas Emerg Nurs J 2007; 10:26-9.

8. College of Emergency Nursing Australasia. Position statement - mechanical ventilation. Sydney: CENA; 2011.

9. Emergency Nurses Association. Procedural sedation consensus statement. 2008 [cited 2010 August]; Available from: http://www.ena.org/about/position/jointstatements/pages/ default.aspx

10. Critical Appraisal Skills Program UK. Making sense of evidence. 2011 [cited 2012 October]; Available from: http://www.casp-uk.net/

11. Green R, Maclntyre J. Critical care in the emergency department: an assessment of the length of stay and invasive procedures on critically ill ED patients. Scand J Trauma Resusc Emerg Med 2009; 17:47.

12. Fromm RJ, Gibbs L, McCallum W, Niziol C, Babcock J, Gueler A, et al. Critical care in the emergency department: a time-based study. Crit Care Med 1993;21:970-6.

13. McCaig L, Nawar E. National Hospital Ambulatory Medical Care Survey: 2004 emergency department summary. Adv Data 2006:1-29.

14. Meggs W, Czaplijski T, Benson N. Trends in emergency department utilization, 1988-1997. Acad Emerg Med 1999;6(10):1030-5.

15. Clark K, Normile L. Patient flow in the emergency department: is timeliness to events related to length of hospital stay? J Nurs Care Qual 2007;22(1):85-91.

16. O'Connor G, Geary U, Moriarty J. Critical care in the emergency department. Eur J Emerg Med 2009;16: 296-300.

17. Graff L, Wolf S, Dinwoodie R, Buono D, Mucci D. Emergency physician workload: a time study. Ann Emerg Med 1993;22:1156-63.

18. Graham C. Critical care in emergency medicine. Eur J Emerg Med 2009; 16:295.

19. Nguyen H, Rivers E, Havstad S, Knoblich B, Ressler J, Muzzin A, et al. Critical care in the emergency department: a physiological assessment and outcome evaluation. Acad Emerg Med 2000;7:1354-61.

20. Bur A, Mullner M, Sterz F, Hirschl M, Laggner A. The emergency department in a 2000-bed teaching hospital: saving open ward and intensive care facilities. Eur J Emerg Med 1997;4(1):19-23.

21. Carter A, Pilcher D, Bailey M, Cameron P, Duke G, Cooper J. Is ED length of stay before ICU admission related to patient mortality? Emerg Med Australas 2010;22: $145-50$.

22. Cardosa L, Grion C, Matsuo T, Anami E, Kauss I, Seko L, et al. Impact of delayed admission to intensive care units on mortality of critically ill patients: a cohort study. Crit Care 2011;15:1-8.

23. Smally A, Nowicki T. Sedation in the emergency department. Curr Opin Anaesthesiol 2007;20(379-383):379.

24. Aitken L, Marshall A, Elliott R, McKinley S. Critical care nurses' decision making: sedation assessment and management in intensive care. J Crit Nurs 2009;18:36-45. 
25. New South Wales Department of Health. Transitioning to practice: emergency nursing program. Sydney: New South Wales Department of Health; 2011.

26. Department of Health and Ageing. Emergency Triage Education Kit; 2009 [cited 2013 January]; Available from: http://www.health.gov.au/internet/main/publishing.nsf / Content/casemix-ED-Triage+Review+Fact+Sheet+Documents

27. Auditor General for Western Australia. Performance examination: a critical resource: nursing shortages and the use of agency nurses. Perth, Australia: Western Australian Government; 2002.

28. Department of Education Science and Training. National review of nursing education 2002. Canberra: Nurse Education and Training; 2002.

29. New South Wales Department of Health. South Eastern Sydney Local Health District. Health services plan 2012-2017; 2012. Sydney.

30. Creasia J, Parker B. Conceptual foundations: the bridge to professional nursing practice. 3rd ed. Toronto: Mosby; 2001.

31. Kramer M. Reality shock: why nurses leave nursing. St. Louis, CV: Mosby; 1974.

32. Leigh J, Howarth M, Devitt P. The role of the lecturer practitioner: an exploration of the stakeholders and practitioners perspective. Nurse Educ Pract 2005;5(5):258-65.

33. National Nursing and Nursing Education Taskforce. National Nursing and Nursing Education Taskforce, final report. Canberra: National Nursing and Nursing Education Taskforce; 2006.

34. Nursing Education Review Secretariat. National review of nursing education. Canberra, ACT: Commonwealth of Australia; 2002.

35. Nehring W, Lashley F. Current use and opinions regarding human patient simulators in nursing education: an international survey. Nurs Educ Perspect 2004;35:244-8.

36. Billet S. Toward a workplace pedagogy: guidance, participation, and engagement. Adult Educ Q 2002;53(1):27-43.

37. Decker S, Sportsman S, Puetz L, Billings L. The evolution of simulation and its contribution to competency. J Contin Educ Nurs 2008;39(2):74-80.

38. Weinert C, Chlan L, Gross C. Sedating critically ill patients: factors affecting nurses' delivery of sedative therapy. Am J Crit Care 2001;10(3):156-65.

39. Guttormson J, Chlan L, Weinert C, Kay S. Factors influencing nurse sedation practices with mechanically ventilated patients: a U.S. national survey. Intensive Crit Care Nurs 2010;26:44-50.

40. Riess M, Graefe U, Goeters C, Van A, Bone H. Sedation assessment in critically all patients with bispectral index. Eur $J$ Anaesthesiol 2002;19(1):18-22.

41. Young C, Knudsen N, Hilton A, Reves JG. Sedation in the intensive care unit. Crit Care Med 2000;28(3):854-66.

42. Calver J, Bulsara M, Boldy D. In-patient hospital use in the last years of life: a Western Australian population-based study. Aust N Z J Public Health 2006;30:146.

43. Olson DM, Thoyre SM, Auyong DB. Perspectives on sedation assessment in critical care. AACN Adv Crit Care 2007; 18(4):380-95.

44. Australian and New Zealand College of Anesthetists. Guidelines on sedation and/or analgesia for diagnostic and interventional medical, dental or surgical procedures. ANZCA; 2010.

45. The American Society of Anethesiologists. Continuum of depth of sedation; definition of general anesthesia and levels of sedation/analgesia; 2009.

46. Coté G, Hovis RM, Ansstas MA, Waldbaum L, Azar RR, Early DS, et al. Incidence of sedation-related complications with propofol use during advanced endoscopic procedures. Clin Gastroenterol Hepatol 2009;8:137-42.
47. Shehabi Y, Chan L, Kadiman S, Alias A, Ismail WN, Tan MA, et al. Sedation depth and long-term mortality in mechanically ventilated critically ill adults: a prospective longitudinal mutlicentre cohort study. Intensive Care Med 2013;39:910-8.

48. Rodrigues GJ, do Amaral J. Influence of sedation on morbidity and mortality in the intensive care unit. Sao Paulo Med J 2004;122(1):8-11.

49. Barr J, Fraser G, Puntillo K, Ely E, Gelinas C, Dasta J, et al. Clinical practice guidelines for the management of pain, agitation, and delirium in adult patients in the Intesive Care Unit. Crit Care Med 2013;41(1):263-306.

50. Aitken L, Marshall A, Elliott R, McKinley S. Critical care nurses' decision making: sedation assessment and management in intensive care. J Crit Nurs 2007;18:36-45.

51. Teasdale G, Jennett B. Assessment of coma and impaired consciousness. A practical scale. Lancet 1974;2(7872):81-4.

52. Proehl J. The Glasgow Coma Scale: do it and do it right. J Emerg Nurs 1992; 18:421-3.

53. Teasdale G, Jennett B. Assessment of coma and impaired consciousness. Lancet 1974;2(7872):81-4

54. Kelly A. Relationships in emergency care: communication and impact. Top Emerg Med 2005;27(3):192-7.

55. Skinner D, Driscoll P, Earlam R, editors. $A B C$ of major trauma. 2nd ed. London: BMJ Publishing Group; 1996.

56. Gill M, Reiley D, Green S. Inter-rater reliability of Glasgow Coma Scale scores in the emergency department. Ann Emerg Med 2004; 43:215-23.

57. Ely EW, Truman B, Shintani A, Thomason JWW, Wheeler AP, Gordon S, et al. Monitoring sedation status over time in ICU patients: Reliability and validity of the Richmond AgitationSedation Scale (RASS). JAMA 2003;289(22):2983-91.

58. Riker R, Fraser G. Monitoring sedation, agitation, analgesia, neuromuscular blockade, and delirium in adult ICU patients. Semin Respir Crit Care Med 2005;22:189-98.

59. Watson BD, Kane-Gill SL. Sedation assessment in critically ill adults: 2001-2004 update. Ann Pharmacother 2004;38:1898-906.

60. Sessler CN. Sedation scales in ICU. Chest 2004;126(6):1727-30.

61. Pun B, Dunn J. The sedation of critically ill adults. Part 1. Assessment. Am J Nurs 2007;107(7):40-8.

62. Pasero C, McCaffrey M. Monitoring sedation. Am J Nurs 2002;102(2):67-9.

63. Elliott D, Aitken L, Bucknall T, Seppelt I, Webb S, Weisbrodt L, et al. Patient comfort in the intensive care unit: a multicentre, binational point prevalence study of analgesia, sedation and delirium management. Crit Care Resusc 2013;15(3):213-9.

64. Ramsay M, Savege T, Simpson B, Goodwin R. Controlled sedation with alphaxalone-alphadolone. BMJ 1974;2:656-9.

65. Riker R, Fraser G, Cox P. Continuous infusion of haloperidol controls agitation in critically ill patients. Crit Care Med 1994;22(3):433-40.

66. Devlin J, Boleski G, Mlynarek M, Narenz D, Peterson E, Jankowski $M$, et al. Motor activity assessment scale: a valid and reliable sedation scale for use with mechanically ventilated patients in an adult surgical intensive care unit. Crit Care Med 1999;27:1271-5.

67. Sessler CN, Gosnell MS, Grap MJ, Brophy GM, O’Neal PV, Keane $\mathrm{KA}$, et al. The Richmond Agitation-Sedation Scale: validity and reliability in adult intensive care unit patients. Am J Respir Crit Care Med 2002;166:1338-44.

68. Fraser GL, Prato BS, Riker RR, Berthiaume D, Wilkins ML. Frequency, severity, and treatment of agitation in young versus elderly patients in the ICU. Pharmacotherapy 2000;20(1):75-82.

69. Jacobi J, Fraser GL, Coursin D, Riker RR, Fontaine D, Wittbrodt $\mathrm{E}$, et al. Clinical practice guidelines for the sustained use of 
sedatives and analgesics in the critically ill adult. Crit Care Med 2002;30:119-41.

70. Mehta S, McCullagh I, Burry L. Current sedation practices: lessons learned form international surveys. Crit Care Clin 2009;25:471-88.

71. Payen J-F, Chanques G, Mantz J, Hercule C, Auriant I, Leguillou J-L, et al. Current practices in sedation and analgesia for mechanically ventilated critically ill patients. Anesthesiology [sic] 2007; 106(687-695):687.

72. Salluh J, Dal-Pizzol F, Mello P, Friedman G, Silva E, Teles J, et al. Delirium recognition and sedation practices in critically ill patients: a survey on the attitudes of 1015 Brazilian critical care physicians. J Crit Care 2009;24(4):556-62.

73. Wunsch H, Kahn J, Kramer A, Rubenfeld G. Use of intravenous infusion sedation among mechanically ventilated patients in the United States. Crit Care Med 2009;37(12):3031-9.

74. Reschreiter $H$, Maiden M, Kapila A. Sedation practice in the intensive care unit: a UK national survey. Crit Care 2008;12(6):152-61.

75. Brook A, Ahrens T, Schaiff R, Prentice D, Sherman G, Shannon $W$, et al. Effect of a nursing-implemented sedation protocol on the duration of mechanical ventilation. Crit Care Med 1999;27:2609-15.

76. Girard T, Kress J, Fuchs B, Thomason J, Schweickert W, Pun $B$, et al. Efficacy and safety of a paired sedation and ventilator weaning protocol for mechanically ventilated patients in intensive care (Awakening and Breathing Controlled trial): a randomised controlled trial. Lancet 2008;371(9607):126-34.

77. Kress J, Pohlman A, O'Connor M, Hall J. Daily interruption of sedative infusions in critically ill patients undergoing mechanical ventilation. N Engl J Med 2000;342:1471.

78. Treggiari M, Romand J, Yanez N, Deem S, Goldberg J, Hudson L, et al. Randomized trial of light versus deep sedation on mental health after critical illness. Crit Care Med 2009;37(9):2527-94.

79. Kollef M, Levy NA, Schaiff TS, Prentice R, Sherman D. The use of continuous IV sedation is associated with prolongation of mechanical ventilation. Chest 1998;114(2):541-8.

80. Kress J, Gehlbach B, Lacy M, Pliskin N, Pohlman A, Hall J. The long-term psychological effects of daily sedative interruption on critically ill patients. Am J Respir Crit Care Med 2003;168(12):1457-61.

81. Kress J, Vinayak A, Levitt J, Schweickert W, Gehlbach B, Zimmerman F, et al. Daily sedative interruption in mechanically ventilated patients at risk for coronary artery disease. Crit Care Med 2007;35(2):365-71.

82. Hall R, MacLaren C, Smith M, Mclntyre A, Allen C, Murphy $\mathrm{J}$, et al. Light versus heavy sedation after cardiac surgery: myocardial ischemia and the stress response. Maritime Heart Centre and Dalhousie University. Anesth Analg 1997;85(5):971-8.

83. Mangano D, Siliciano D, Hollenberg M, Leung J, Browner W, Goehner P, et al. Postoperative myocardial ischemia, Therapeutic trials using intensive analgesia following surgery. The Study of Perioperative Ischemia (SPI) Research Group. Anesthesiology 1992;76(3):342-53.
84. Plunkett J, Reeves J, Ngo L, Bellows W, Shafer S, Roach G, et al. Urine and plasma catecholamine and cortisol concentrations after myocardial revascularization, Modulation by continuous sedation. Multicenter Study of Perioperative Ischemia (MCSPI) Research Group, and the Ischemia Research and Education Foundation (IREF). Anesthesiology 1997;86(4):785-96.

85. Terao Y, Miura K, Saito M, Sekino M, Fukusaki M, Sumikawa K. Quantitative analysis of the relationship between sedation and resting energy expenditure in postoperative patients. Crit Care Med 2003;31(3):830-3.

86. Samuelson K, Lundberg D, Frindlund B. Light vs. heavy sedation during mechanical ventilation after oesophagectomy - a pilot experimental study focusing on memory. Acta Anesthesiol Scand 2008;52:1116-23.

87. Samuelson K, Lundberg D, Fridlund B. Stressful experiences in relation to depth of sedation in mechanically ventilated patients. Nurs Crit Care 2007;12(2):93-104.

88. Samuelson K, Lundberg D, Fridlund B. Memory in relation to depth of sedation in adult mechanically ventilated intensive care patients. Intensive Care Med 2006;32(5):660-7.

89. Sessler CN, Grap MJ, Brophy GM. Multidisciplinary management of sedation and analgesia in critical care. Semin Respir Crit Care Med 2001;22:211-25.

90. Carrion M, Ayuso D, Marcos M, Paz Robles M, de la Cal M, Alía I, et al. Accidental removal of endotracheal and nasogastric tubes and intravascular catheters. Crit Care Med 2000;28(63-66):63.

91. Riker R, Picard J, Fraser G. Prospective evaluation of the Sedation-Agitation Scale for adult critically ill patients. Care Med 1999;27:1325-9.

92. Dawson R. Sedation assessment using the Ramsey scale. Emerg Nurse 2010;18(3):18-20.

93. American Nurses Association. Endorsement of position statement on the role of the registered nurse (RN) in the management of patients receiving IV conscious sedation for short-term therapeutic, diagnostic, or surgical procedures. USA: ANA; 1991

94. American Association of Nurse Anaesthetists. Scope and standards for nurse anesthesia practice; 2008.

95. National Emergency Nurses Affiliation. Position statement: procedural sedation. Canada: NENA; 2009.

96. The Association of Anaesthetists of Great Britain and Ireland. Recommendations for standards of monitoring during anaesthesia and recovery; 2007.

97. The Royal College of Anaesthetists. A guide for departments of anaesthesia, critical care and pain management. UK: Joint Committee on Good Practice; 2006.

98. American College of Emergency Physicians. Rapid sequence intubation. Ann Emerg Med 1997;29:573.

99. American College of Emergency Physicians. Clinical policy: procedural sedation and analgesia in the emergency department. Ann Emerg Med 2005;45(2):177-96.

100. American Society of Anethesiologists Task Force. Practice guidelines for sedation and analgesia by non-anesthesiologists. Anesthesiology 2002;96:1004-17. 